TẠP CHÍ KHOA HỌC ĐẠI HỌC TÂN TRÀO
ISSN: 2354 - 1431

\title{
Lựa chọn ứng dụng hệ thống bài tập thúc đẩy quá trình hồi phục sau tập luyện và thi đấu cho vận động viên bóng đá trẻ lứa tuổi 14 - 15 của Trung tâm Thể dục thể thao Trường Đại học Tân Trào
}

Nguyễn Văn Hải ${ }^{a^{*}}$

${ }^{a}$ Trưòng Đại học Tân Trào

*Email: nguyenhaidhtt@gmail.com

Thông tin bài viết

Ngày nhận bài:

17/12/2019

Ngày duyệt đăng:

$10 / 3 / 2020$

Tù khóa:

bài tập hồi phuc; bóng đá

trẻ; Truờng Đại Học Tân

Trào.

\section{Tóm tắt}

Nghiên cứu này tiến hành lựa chọn và ứng dụng hệ thống bài tập thúc đẩy quá trình hồi phục sau tập luyện và thi đấu cho vận động viên bóng đá trẻ lứa tuổi 14 - 15 của Trung tâm Thể dục thể thao Trường Đại Học Tân Trào, Tuyên Quang.

\section{1. Đặt vấn đề}

Việc sử dụng khối lượng và cường độ vận động lớn trong huấn luyện nâng cao thành tích là một xu thế của huấn luyện hiện đại. Sau tập luyện và thi đấu với lượng vận động lớn và căng thẳng, nếu cơ thể được hồi phục tốt sẽ giúp cho vận động viên (VĐV) nhanh chóng thích nghi với lượng vận động mới, thành tích sẽ được nâng lên, ngược lại, hồi phục chậm sẽ gây mệt mỏi sâu, làm giảm khả năng hoạt động và có thể dẫn tới chấn thương trong tập luyện và thi đấu.

Những năm gần đây, việc nghiên cứu ứng dụng hệ thống bài tập thúc đẩy khả năng hồi phục cho VĐV rất được các nhà khoa học trên thế giới quan tâm và nghiên cứu nhằm nâng cao hiệu quả huấn luyện. Tuy nhiên, ở Việt Nam việc nghiên cứu các bài tập hồi phục tích cực sau vận động còn hạn chế, đặc biệt đối với các đội bóng đá trẻ ở các tỉnh khu vực miền núi phía bắc thì việc phục hồi sau tập luyện và thi đấu, các bài tập đưa ra hầu hết từ kinh nghiệm cá nhân của các huấn luyện viên (HLV) mà chưa có công trình nghiên cứu nào đánh giá hiệu quả của các bài tập đó, vì vậy vấn đề nghiên cứu có tính cấp thiết và có giá trị thực tiễn cao.

\section{Phương pháp nghiên cứu}

Quá trình nghiên cứu đã sử dụng các phương pháp sau: Phương pháp phân tích và tổng hợp tài liệu, phương pháp phỏng vấn, phương pháp quan sát sư phạm, phương pháp kiểm tra $\mathrm{y}$ học, phương pháp kiểm tra sư phạm, phương pháp toán học thống kê.

\section{Kết quả nghiên cứu}

3.1. Thục trạng công tác hồi phục tích cục sau tập luyện và thi đấu cho VĐV bóng đá lứa tuổi 14-15 của Trung tâm TDTT Truò̀ng Đại Học Tân Trào Tuyên Quang.

Bằng phương pháp quan sát sư phạm 10 giáo án huấn luyện cho thấy: Hồi phục sau các buổi tập chủ yếu sử dụng các bài tập ưa khí với thời lượng 20 phút như: chạy nhẹ nhàng quanh sân tập chiếm 13,3\%; đi bộ kết hợp thở sâu $16,6 \%$...; các bài tập duỗi cơ, thả lỏng và hoạt động thường xuyên, $\mathrm{VĐV}$ tự giác tích cực thực hiện các bài tập hồi phục. 
3.2. Lụa chọn và đánh giá hiệu quả hệ thống bài tập thúc đẩy quá trình hồi phục tích cực sau tập luyện và thi đấu cho V円V Bóng đá lứa tuổi 14-15 tại Trung tâm TDTT Truòng Đại Học Tân Trào Tuyên Quang

3.2.1. Xác định các yêu cầu trong lựa chọn bài tập hồi phục tích cực

Dựa vào tài liệu tham khảo, đề tài lựa chọn các bài tập thúc đẩy hồi phục sau buổi tập luyện và thi đấu như sau:

- Bài tập có hệ thống theo một trình tự khoa học, đảm bảo sự phối hợp để thúc đẩy và phát huy hiệu quả.

- Bài tập hợp lý phù hợp với đặc điểm và nội dung của buổi tập.

- Bài tập có tính khả thi có thể thực hiện được ngay sau khi tập luyện.

- Bài tập đảm bảo tính khách quan và độ tin cậy các bài tập có đơn vị đo lường cụ thể, có qui định cấu trúc chặt chẽ.

Sau khi đã xác định được 4 yêu cầu, để đảm bảo tính khách quan và độ tin cậy trong việc lựa chọn và xây dựng bài tập hồi phục tích cực sau buổi tập cho $\mathrm{VĐV}$, đề tài tiến hành phỏng vấn 15 nhà khoa học, giáo viên, chuyên gia, huấn luyện viên trong và ngoài Trung tâm nhằm đánh giá tính khoa học và mức độ quan trọng của các yêu cầu đưa ra. Kết quả phỏng vấn đã cho thấy ý kiến đồng thuận cao của các đối tượng tham gia phỏng vấn.

3.2.2. Lựa chọn hệ thống bài tập nhằm thúc đẩy quá trình hồi phục tích cưc sau giờ tập cho VĐV Bóng đá lứa tuổi 14-15 của Trung tâm TDTT Truờng Đại Học Tân Trào Tuyên Quang

Căn cứ vào các yêu cầu đặt ra, từ kết quả tham khảo tài liệu đề tài bước đầu đã lựa chọn được 22 bài tập thúc đẩy hồi phục sau buổi tập luyện và thi đấu và được phân theo 4 nhóm:

Nhóm bài tập ưa khí (5 bài tập). Mục đích: nhằm trả nợ oxy, hồi phục ATP - CP, tăng oxy hóa acid lactic và đào thải các sản phẩm trao đổi chất.

Nhóm bài tập căng duỗi cơ (5 bài tập). Mục đích: tăng tuần hoàn máu và bạch huyết; thúc đẩy quá trình trao đổi chất.

Nhóm bài tập thả lỏng (4 bài tập). Mục đích: giúp máu lưu thông được dễ dàng hơn, dịch gian bào phân bố đều, giúp cơ được thả lỏng và giảm bớt sự căng thẳng.

Nhóm bài tập hoạt động thụ động (3 bài). Mục đích: tăng đàn tính của cơ và dây chằng, tăng độ linh hoạt của khớp, giải phóng sự chèn ép dọc tới mạch máu và thần kinh, phòng ngừa các di chứng chấn thương.

Để làm tăng thêm tính khách quan trong việc lựa chọn các bài tập đề tài đã tiến hành phỏng vấn đối với 15 nhà khoa học, giáo viên, chuyên gia, huấn luyện viên trong và ngoài trường. Kết quả cho thấy: Trong 22 bài tập đưa ra phỏng vấn có 12 bài tập được các giáo viên, $\mathrm{HLV}$, chuyên gia đánh giá cao và đạt từ $73,3 \%$ tổng số phiếu trở lên. Theo nguyên tắc đặt ra các bài tập này được đề tài lựa chọn để tiến hành thử nghiệm bao gồm:
A. Nhóm bài tập ưa khí:
2. Vươn thở.
B. Nhóm bài tập căng duỗi co:
3. Căng các cơ khu đai vai.
4. Căng duỗi cơ ngực.
5. Căng duỗi các cơ vùng thắt lưng.
6. Căng duỗi cơ tứ đầu đùi.
7. Ép ngang, ép dọc.
C. Nhóm bài tập thả lỏng:
8. Rung, lắc, rũ, cơ chân, tay.
9. Phơi cá.

1. Chạy nhẹ nhàng kết hợp hít thở sâu, cự ly 150m.

\section{Nhóm bài tập hoạt động thụ động:}

10. Hoạt động thụ động liên hoàn chi trên.

11. Hoạt động thụ động liên hoàn chi dưới.

12. Hoạt động thụ động liên hoàn toàn thân.

3.3. Nghiên cứu úng dụng các bài tập đã lụa chọn để thúc đẩy quá trình hồi phục tích cục sau tập luyện và thi đấu cho VĐV bóng đá lứa tuổi 14-15 tại Trung tâm TDTT Truờng Đại Học Tân Trào

\subsubsection{Tổ chức thực nghiệm}

Phuoong pháp: tiến hành theo hình thức thực nghiệm sư phạm so sánh song song. 2 nhóm được phân một cách ngẫu nhiên với số lượng mỗi nhóm $10 \mathrm{VĐV}$.

Nội dung thực nghiệm: Là hệ thống bài tập thúc đẩy quá trình hồi phục tích cực mà đề tài đã lựa chọn.

Thời gian thực hiện/giáo án huấn luyện: $15-20$ phút.

Thư tụ sư dụng các bài tập: Bài tập ưa khí, duỗi cơ, thả lỏng, thụ động hoạt động. Yêu cầu: thực hiện đủ cả 4 nhóm theo trình tự, căn cứ nội dung huấn luyện để lựa chọn $2-3$ bài trong nhóm bài tập duỗi cơ. 
3.3.2. Đánh giá hiệu quả các bài tập đã lựa chọn để thúc đẩy quá trình hồi phuc tích cưc sau giờ tạp cho $V Ð V$

Để đánh giá hiệu quả ứng dụng các bài tập đã lựa chọn đề tài tiến hành sử dụng 5 test đã lựa chọn để kiểm tra đánh giá khả năng hồi phục và so sánh kết quả thu được ở 2 thời điểm: trước thực nghiệm và sau thực nghiệm giữa nhóm thực nghiệm và nhóm đối chứng.

Kết quả kiểm tra trước thực nghiệm cho thấy ở cả 5 test giữa 2 nhóm không có sự khác biệt. Điều đó có nghĩa trước thực nghiệm khả năng hồi phục của 2 nhóm là tương đồng, không có sự khác biệt.

Để đánh giá hiệu quả các bài tập thúc đẩy hồi phục tích cực sau buổi tập đã được đề tài lựa chọn, đề tài tiến hành kiểm tra các Test sau ba tháng thực nghiệm. Kết quả được trình bày ở bảng 1 .

Bảng 1. Kết quả so sánh mức độ hồi phục giũa 2 nhóm đối chứng và thực nghiệm sau thời gian thực nghiệm

\begin{tabular}{|c|l|c|c|c|c|c|c|}
\hline \multirow{2}{*}{ Stt } & \multirow{2}{*}{$\begin{array}{c}\text { Các test } \\
\text { kiểm tra }\end{array}$} & \multicolumn{6}{|c|}{ Kết quả kiểm tra } \\
\cline { 3 - 8 } & \multicolumn{2}{|c|}{$\mathbf{D C}(\mathbf{n}=\mathbf{1 0})$} & \multicolumn{2}{|c|}{ TN $(\mathbf{n}=\mathbf{1 0})$} & \multicolumn{2}{|c|}{ So sánh } \\
\hline 1 & $\begin{array}{l}\text { Tần số mạch } \\
\text { (lần/phút) }\end{array}$ & 75.5 & 0.57 & 73.6 & 0.58 & 2.71 & $<0.05$ \\
\hline 2 & $\begin{array}{l}\text { Tần số hô hấp } \\
\text { (lần/phút) }\end{array}$ & 17.5 & 0.76 & 15.8 & 0.54 & 3.15 & $<0.01$ \\
\hline 3 & $\begin{array}{l}\text { Teppy test } \\
\text { (chấm/s) }\end{array}$ & 5.9 & 0.47 & 6.6 & 0.43 & 6.54 & $<0.001$ \\
\hline 4 & $\begin{array}{l}\text { Cảm giác lực } \\
\text { cơ (g) }\end{array}$ & 4.1 & 0.47 & 3.4 & 0.37 & 6.14 & $<0.001$ \\
\hline 5 & $\begin{array}{l}\text { Đi thăng bằng } \\
5 \text { mét (điểm) }\end{array}$ & 6.3 & 0.43 & 7.4 & 0.35 & 9.28 & $<0.001$ \\
\hline
\end{tabular}

So sánh kết quả kiểm tra ở cả 5 test sau khi sử dụng các bài tập thúc đẩy quá trình hồi phục cho nhóm thực nghiệm cho thấy $\mathrm{t}_{\text {tinh }}>\mathrm{t}_{\text {bang }}=2,228$ có sự khác biệt có ý nghĩa thống kê ở ngưỡng sác xuất $\mathrm{p}<0,05$ $\mathrm{p}<0,001$ so với nhóm đối chứng. Như vậy mức độ hồi phục của hai nhóm có sự khác biệt. Sau buổi tập, quá trình hồi phục đã diễn ra ở cả 2 nhóm, tuy nhiên mức độ hồi phục ở nhóm thực nghiệm đạt được tốt hơn so với nhóm đối chứng. Kết quả này đã minh chứng cho hiệu quả ứng dụng của các bài tập mà đề tài đã lựa chọn trong việc thúc đẩy hồi phục cho VĐV Bóng đá lứa tuổi 14-15 sau tập luyện và thi đấu.

\section{Kết luận}

Từ kết quả nghiên cứu cho phép rút ra một số kết luận sau:

4.1. Kết quả nghiên cứu thực trạng sử dụng các bài tập thúc đẩy quá trình hồi phục tích cực sau tập luyện và thi đấu cho VĐV Bóng đá lứa tuổi 14-15 tại Trung tâm TDTT Trường Đại Học Tân Trào Tuyên Quang, cho thấy chủ yếu là bài tập ưa khí, các bài tập tập duỗi cơ, thả lỏng và các bài tập hoạt động thụ động chưa thường xuyên được sử dụng. Số lượng bài tập còn hạn chế, các VĐVchưa tự giác tích cực và chưa thực hiện thống nhất các bài tập hồi phục.

4.2. Nghiên cứu đã lựa chọn 12 bài tập thúc đẩy hồi phục tích cực sau buổi tập, được phân theo 4 nhóm: Bài tập ưa khí (2 bài tập) Bài tập căng duỗi cơ (5 bài tập); Bài tập thả lỏng ( 2 bài) và xây dựng kế hoạch thực nghiệm: Thời gian thực hiện - 15 phút; Trình tự thực hiện - Bài tập ưa khí, duỗi cơ, thả lỏng và thụ động hoạt động. Kết quả thực nghiệm đã minh chứng cho hiệu quả thúc đẩy quá trình hồi phục của các bài tập mà nghiên cứu đã lựa chọn.

\section{TÀI LIỆU THAM KHẢO}

1. Bộ Giáo dục và Đào tạo (2008), Tiêu chuẩn đánh giá thể lực cho sinh viên của bộ GD\&ĐT được ban hành tại quyết định 53/2008/QĐ-BGDDT ngày 18/9/2008.

2. Lê Hữu Hưng, Vũ Chung Thủy, Nguyễn Thanh Nhàn (2010), Hồi phục \& Vật lý trị liệu, Nxb Thể dục thể thao, Hà Nội.

3. Lê Hữu Hưng, Vũ Chung Thủy, Nguyễn Thanh Nhàn (2013), Kiểm tra Y hoc thể duc thể thao, Nxb Thể dục thể thao, Hà Nội.

4. Lê Văn Lẫm - Phạm Xuân Thành (2008), Giáo trình Thể duc thể thao trường học, Nxb Nxb Thể dục thể thao, Hà Nội 
Selecting application of the training system to promote the recovery process after training and competing for the young footballers at the age 14 to 15 of The Sport Center at Tan Trao University

Nguyen Van Hai

Article info

Recieved:

$17 / 12 / 2019$

Accepted:

$10 / 3 / 2020$

Keywords:

Recovery exercises;

young football; Tan Trao

University

\begin{abstract}
This research carried out the selection and application of the exercise system to promote the recovery process after training and competing for young footballers at the age 14 to 15 of the Sports Center at Tan Trao University, Tuyen Quang province.
\end{abstract}

